Article

\title{
Vine Shoots and Grape Stalks as Carbon Sources for Hydrogen Evolution Reaction Electrocatalyst Supports
}

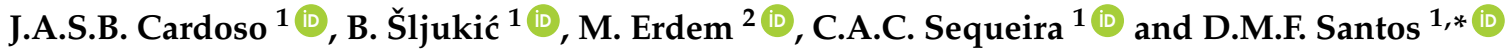 \\ 1 Center of Physics and Engineering of Advanced Materials (CeFEMA), Instituto Superior Técnico, \\ Universidade de Lisboa, 1049-001 Lisbon, Portugal; jose.asb.cardoso@gmail.com (J.A.S.B.C.); \\ biljana.paunkovic@tecnico.ulisboa.pt (B.Š.); cesarsequeira@tecnico.ulisboa.pt (C.A.C.S.) \\ 2 Department of Environmental Engineering, Firat University, 23279 Elazı $\breve{g}$, Turkey; merdem@firat.edu.tr \\ * Correspondence: diogosantos@tecnico.ulisboa.pt; Tel.: +351-21-841-7765
}

Received: 29 November 2017; Accepted: 25 January 2018; Published: 27 January 2018

\begin{abstract}
Activated bio-based carbons produced from vine shoots (VSAC) and grape stalks (GSAC), which have larger surface area and total pore volume than most of the commercially available activated carbons, are used as supports for palladium nanoparticles (Pd NPs). The prepared materials are characterised by elemental analysis, $\mathrm{N}_{2}$-sorption, $\mathrm{X}$-ray diffraction, scanning electron microscopy with energy dispersive $\mathrm{X}$-ray spectroscopy, and transmission electron microscopy analysis and are then assessed as potential cathodes for the hydrogen evolution reaction (HER) in alkaline media. The electrocatalysts' performance for HER is evaluated from cathodic polarisation curves at different temperatures and compared to that of Vulcan XC72-supported Pd NPs. Additional chronoamperometry studies helped to assess the electrocatalysts' activity stability. The novel VSAC-supported Pd electrocatalyst exhibits good HER activity in terms of high current density at low overpotentials, leading to the best performance.
\end{abstract}

Keywords: palladium nanoparticles; bio-based activated carbon; alkaline water electrolysis; hydrogen evolution reaction

\section{Introduction}

Due to the problems arising from the consumption of fossil fuels [1], alternative energy carriers inevitably have to become a part of the energy industry in the near future. One of the most promising alternatives to fossil fuels is hydrogen, as it has a large combustion heat $\left(287 \mathrm{~kJ} \mathrm{~mol}^{-1}\right)$ and the only waste produced by its consumption is water [2]. For this reason, extensive research has been carried out by scientists all over the world in order to make the production and storage technology for hydrogen as efficient as possible [3]. Water electrolysis has been proven to be an exceptionally interesting method for hydrogen production, even more so when powered by renewable energy sources [4]. This is a quite simple method, where a difference in potential between two electrolyte-immersed electrodes is created by applying an external current to a circuit, resulting in the splitting of the water molecule into hydrogen $\left(\mathrm{H}_{2}\right)$ and oxygen $\left(\mathrm{O}_{2}\right)$.

When the electrolyte solution is alkaline (the case for this study), the electrolysis process can be summarised by Equations (1)-(3), where $\mathrm{H}_{2}$ is produced at the cathode and $\mathrm{O}_{2}$ is produced at the anode [5].

$$
\begin{array}{ccc}
\text { Anode: } & 2 \mathrm{OH}^{-} \rightarrow 1 / 2 \mathrm{O}_{2}+\mathrm{H}_{2} \mathrm{O}+2 \mathrm{e}^{-}, & E^{0}=0.40 \mathrm{~V} \text { vs. SHE. } \\
\text { Cathode: } & 2 \mathrm{H}_{2} \mathrm{O}+2 \mathrm{e}^{-} \rightarrow \mathrm{H}_{2}+2 \mathrm{OH}^{-}, & E^{0}=-0.83 \mathrm{~V} \text { vs. SHE. } \\
\text { Global: } \quad \mathrm{H}_{2} \mathrm{O} \rightarrow \mathrm{H}_{2}+1 / 2 \mathrm{O}_{2}, & E_{0}=1.23 \mathrm{~V} .
\end{array}
$$


Since the focus will be on the reactions at the cathode, where the hydrogen evolution reaction (HER) takes place, it is important to detail the various steps through which Equation (2) can occur. The HER in alkaline media is a multistep sequence described by Equations (4)-(6) [6].

$$
\begin{gathered}
\text { Volmer step: } \quad \mathrm{M}+\mathrm{H}_{2} \mathrm{O}+\mathrm{e}^{-} \rightarrow \mathrm{MH}_{\mathrm{ads}}+\mathrm{OH}^{-} . \\
\text {Tafel step: } \quad 2 \mathrm{MH}_{\mathrm{ads}} \rightarrow 2 \mathrm{M}+\mathrm{H}_{2} . \\
\text { Heyrovský step: } \quad \mathrm{MH}_{\mathrm{ads}}+\mathrm{H}_{2} \mathrm{O}+\mathrm{e}^{-} \rightarrow \mathrm{M}+\mathrm{H}_{2}+\mathrm{OH}^{-} .
\end{gathered}
$$

The reaction always begins with the Volmer step (Equation (4)), where the water molecule is split into $\mathrm{H}_{\mathrm{ads}}$ and $\mathrm{OH}^{-}$, which is then followed by either the Tafel (Equation (5)) or the Heyrovský step (Equation (6)). These represent either a chemical or electrochemical (respectively) desorption of the $\mathrm{H}_{2}$ molecule. In order for all these steps to take place, the potential difference between the cathode and the anode has to be large enough to overcome the reversible cell potential, the electrode overpotentials, and the ohmic drop [7]. The latter originates from barriers such as electrodes and electrolyte phases, boundary layers, and electrical resistances at the circuit level [5]. To make the electrolysis cell as efficient as possible, it is imperative to use electrocatalysts that reduce the energy necessary for splitting the water molecule.

Activity towards the HER (achieved by proper control of the reaction mechanism and kinetics) and stability are essential requirements of these electrocatalysts [8]. In this context, platinum $(\mathrm{Pt})$ is the most active and stable electrode material, but its limited supplies and exceptionally high cost pose restrictions for application in large-scale alkaline water electrolysers [9]. Transition metals, their alloys, and compounds, namely, carbides, sulphides, nitrides, phosphides, selenides, and oxides, have been studied as alternative electrocatalysts for HER [10,11]. Among these, molybdenum (Mo) and tungsten (W) carbides [12,13], sulphides [14,15], phosphides [16,17], and selenides [18] showed the most promising behaviour. Still, their HER performance in terms of activity and durability often does not reach that of noble metal-based electrocatalysts.

In contrast, palladium (Pd)-based electrocatalysts have shown great promise as an alternative to the Pt benchmark [19], as Pd possesses some of the qualities of Pt, such as the intermediate hydrogen binding energy and high exchange current density, while being cheaper [20,21]. Due to the higher catalytic activity shown by nanostructured metal electrocatalysts, when compared to the bulk metal electrocatalysts [22], there is a great interest in studying nanostructured forms of $\mathrm{Pd}$, such as $\mathrm{Pd}$ nanoparticles (NPs).

These metal NPs can be anchored on a variety of supports to further increase their catalytic activity. The supports can improve the electrochemical surface area, as well as the distribution of the NPs, thus increasing the conductivity of the catalyst [20]. Recently, different forms of carbon-based materials have been studied for HER applications [23,24]. Bio-based carbon supports have been showing great promise in the area of electrochemical energy conversion devices, even surpassing the results obtained with the commonly used Vulcan XC72 carbon black [25,26]. Namely, commonly used commercial activated carbons have surface area in the range of $500-1500 \mathrm{~m}^{2} \mathrm{~g}^{-1}$, total pore volume higher than $0.2-0.6 \mathrm{~cm}^{3} \mathrm{~g}^{-1}$, and carbon content of $85-95 \%$, and are generally expensive. Vine shoots and grape stalks are low-cost precursors and suitable materials for activated carbon production. The activated carbons produced from these biomaterials by chemical activation have larger surface area and total pore volume and higher carbon content than do most of the commercially available ones. In order to increase catalytic activity, these activated carbons were used as support materials.

In this work, monodispersed Pd NPs supported on three different carbon materials were used as the electrocatalysts. Two of the supports were novel, low-cost, activated biomass-derived carbons, namely, vine shoot activated carbon (VSAC) prepared from vine shoots [27] and grape stalk activated carbon (GSAC) prepared from grape stalks [28]. For comparison purposes, the third support material tested was Vulcan XC72, a benchmark carbon support widely used in industrial applications [26]. 
The activity towards the HER of the three electrocatalysts in alkaline media was studied by linear scan voltammetry (LSV) and chronoamperometry (CA).

\section{Results and Discussion}

\subsection{Characterisation of Bio-Based Activated Carbon Supports}

Bio-based activated carbons (VSAC and GSAC) used as support material were characterised by BET surface area, total pore volume, pore size, $\mathrm{pH}_{\mathrm{pzc}}$ (which indicates the $\mathrm{pH}$ value at which the sample's net surface charge is zero [29]), surface functional group analysis by Boehm's titration, and elemental and SEM analysis. The BET surface area, total pore volume, pore size, and $\mathrm{pH}_{\mathrm{pzc}}$ of the VSAC were found to be $1689 \mathrm{~m}^{2} \mathrm{~g}^{-1}, 0.842 \mathrm{~cm}^{3} \mathrm{~g}^{-1}, 1.941 \mathrm{~nm}$, and 4.8 , respectively, and the VSAC has mainly acidic functional groups (total $0.2516 \mathrm{meq}^{-1}$ ) on its surface. The external surface of the VSAC is highly porous with cracks, channels, cavities, and large holes (Figure 1A). The observed macropores can facilitate gas and electrolyte transportation. The elemental composition of VSAC was found to be $89.65 \%$ C, $0.71 \% \mathrm{H}, 1.58 \% \mathrm{~N}, 0.06 \% \mathrm{~S}$, and $8.00 \% \mathrm{O}$. Similarly, it has been determined that the BET surface area, total pore volume, pore size, and $\mathrm{pH}_{\mathrm{pzc}}$ of the GSAC were $1411 \mathrm{~m}^{2} \mathrm{~g}^{-1}$, $0.723 \mathrm{~cm}^{3} \mathrm{~g}^{-1}, 2.049 \mathrm{~nm}$, and 2.84, respectively, and the activated carbon has acidic surface functional groups and a highly porous surface with cracks, channels, and large holes (Figure 1B). It consists of $92.41 \% \mathrm{C}, 0.28 \% \mathrm{H}, 1.27 \% \mathrm{~N}, 0.17 \% \mathrm{~S}$, and $5.87 \% \mathrm{O}$. Figure 1 clearly shows that VSAC has a more ordered morphology than GSAC, having larger macropores but containing a superior number of nanopores, which is reflected in the much higher BET surface area of the former.

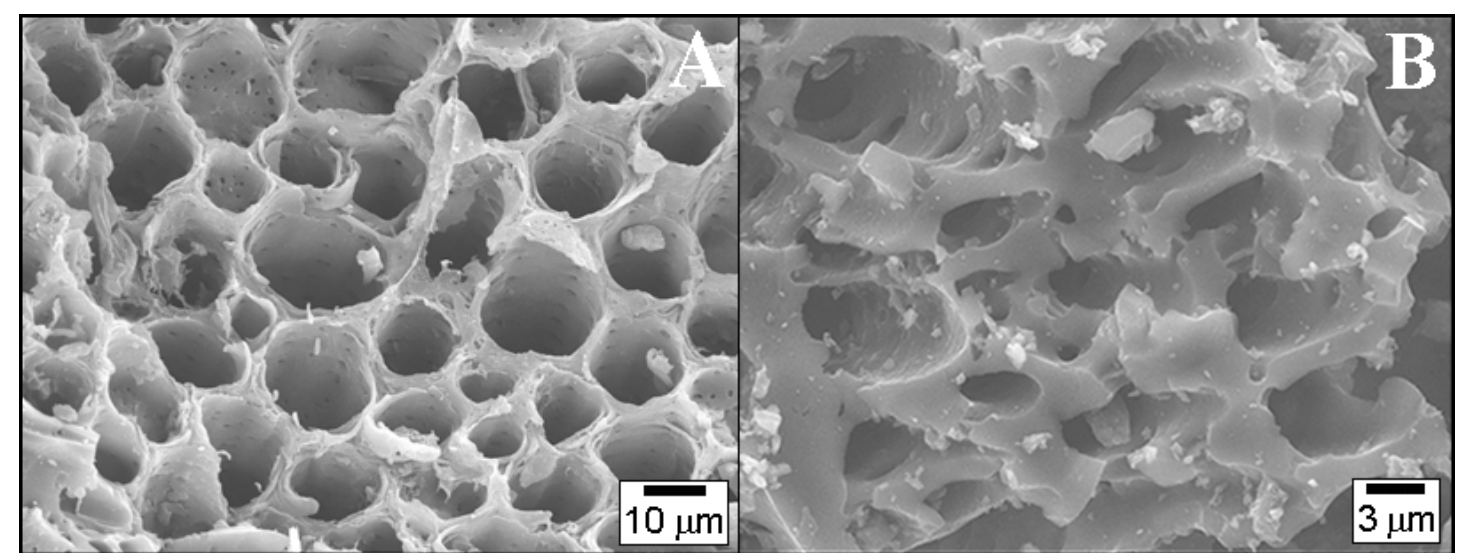

Figure 1. SEM images of (A) vine shoot activated carbon (VSAC) and (B) grape stalk activated carbon (GSAC) support materials $[27,28]$.

Table 1 also includes the textural properties of commercial Vulcan XC72 carbon black for direct comparison of the three tested supports' characteristics. Some other properties of both bio-based activated carbon specimens can be found in the studies of Özdemir et al. [28].

Table 1. Textural characteristics of the three carbon supports.

\begin{tabular}{cccc}
\hline Support Material & BET Surface Area $/ \mathbf{m}^{\mathbf{2}} \mathbf{g}^{\mathbf{- 1}}$ & Total Pore Volume $/ \mathbf{c m}^{\mathbf{3}} \mathbf{g}^{\mathbf{- 1}}$ & Pore Size/nm \\
\hline VSAC & 1689 & 0.84 & 1.9 \\
GSAC & 1411 & 0.72 & 2.1 \\
Vulcan & 224 & 0.47 & 11 \\
\hline
\end{tabular}




\subsection{Characterisation of the Activated Carbon-Supported Pd Nanoparticles}

XRD analysis revealed the face-centred cubic (fcc) structure of crystalline Pd with its main characteristic maxima appearing at $2 \theta$ of ca. $40^{\circ}$ (reflection of (111) plane), $46^{\circ}$ (reflection of (200) plane), and $67^{\circ}$ (reflection of (220) plane) (Figure 2A). A diffraction maximum characteristic for carbon supports appears as well, at $2 \theta$ of ca. $25^{\circ}$. The peak at ca. $2 \theta=11^{\circ}$ probably belongs to the gallic acid $\left(\mathrm{C}_{7} \mathrm{H}_{6} \mathrm{O}_{5} \mathrm{H}_{2} \mathrm{O}\right)$ originating from the activated carbon. The composition and morphology of the three electrocatalysts were further investigated by SEM-EDX and TEM (Figure 2). $\mathrm{Pd} /$ VSAC and Pd/Vulcan exhibit well-dispersed Pd NPs, with some degree of agglomeration in the case of Pd/GSAC. In fact, the TEM image of Pd/GSAC (Figure 2F) presents a high contrast between the areas of particle aggregation and those with higher dispersion, whereas the contrast in $\mathrm{Pd} /$ VSAC (Figure 2C) is much subtler, suggesting a considerably better dispersion of this catalyst. Particularly, the absence of aggregation in Pd/VSAC due to an excellent dispersion of Pd NP decoration (Figure 2B,C) on the bio-based substrate should favour the electrocatalyst surface area and catalytic activity. TEM micrographs were used to determine the Pd NP size distribution in the electrocatalysts. The obtained particle size distribution histograms (insets of Figure 2) reveal that the most abundant $\mathrm{Pd}$ NPs in case of Pd/VSAC, Pd/GSAC, and Pd/Vulcan electrocatalysts are those with diameters of ca. 2-3, 3, and 3-4 nm, respectively. Accordingly, the average Pd particle diameter was evaluated to be 2.7, 2.9, and $3.1 \mathrm{~nm}$ in Pd/VSAC, Pd/GSAC, and Pd/Vulcan, respectively. EDX analysis (Figure 2D,G,J) carried out during SEM confirmed the presence of $\mathrm{Pd}, \mathrm{C}$, and $\mathrm{O}(>1 \%)$ in the three electrocatalysts. The Pd content was determined to be $4.3 \%$ for Pd/Vulcan, $6.9 \%$ for Pd/VSAC, and $21.8 \%$ for Pd/GSAC.

Electrochemical characterisation of the three studied electrocatalysts was performed by recording cyclic voltammetry $(\mathrm{CV})$ studies in deaerated $8 \mathrm{M} \mathrm{KOH}$ at room temperature. CVs of all three materials exhibited characteristic peaks of Pd-based electrocatalysts (Figure $3 \mathrm{~A}$ shows the CV of Pd/Vulcan as an illustrative example). Thus, an anodic peak corresponding to desorption of the stored hydrogen followed by a second anodic peak corresponding to the adsorption of $\mathrm{OH}^{-}$appear in the 0.06-0.65 $\mathrm{V}$ region with a subsequent increase of current corresponding to the formation of the PdO layer at potentials higher than $0.75 \mathrm{~V}$. On the reverse scan, a cathodic peak originating from the reduction of $\mathrm{PdO}$ appears at ca. $0.65 \mathrm{~V}$, followed by hydrogen adsorption at potentials lower than $0.3 \mathrm{~V}$. Furthermore, the charge corresponding to the PdO reduction peak was used for the determination of the electrochemical surface area (ECSA) of Pd-based electrodes. By assuming a monolayer of $\mathrm{PdO}$ and a specific charge value of $420 \mu \mathrm{C} \mathrm{cm}^{-2}$ for the reduction of the PdO monolayer, the ECSA of the Pd electrodes were evaluated to increase in the order $\mathrm{Pd} / \mathrm{VSAC}<\mathrm{Pd} /$ Vulcan $<\mathrm{Pd} / \mathrm{GSAC}$. 


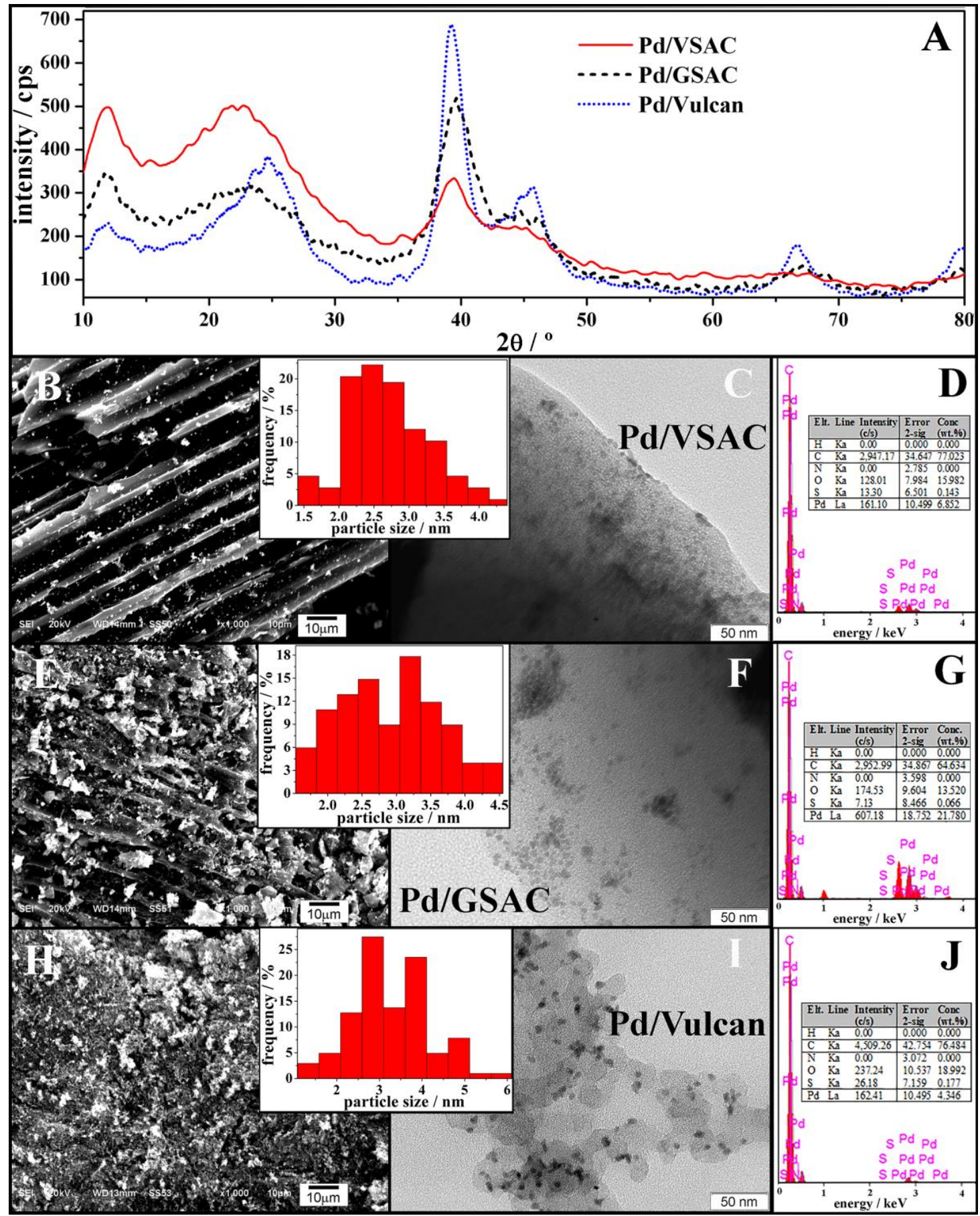

Figure 2. (A) XRD along with SEM and TEM images and EDX data of (B,C,D) Pd/VSAC, $(\mathbf{E}, \mathbf{F}, \mathbf{G}) \mathrm{Pd} / \mathrm{GSAC}$, and $(\mathbf{H}, \mathbf{I}, \mathbf{J}) \mathrm{Pd} /$ Vulcan. Particle size distribution histograms are shown as insets. 

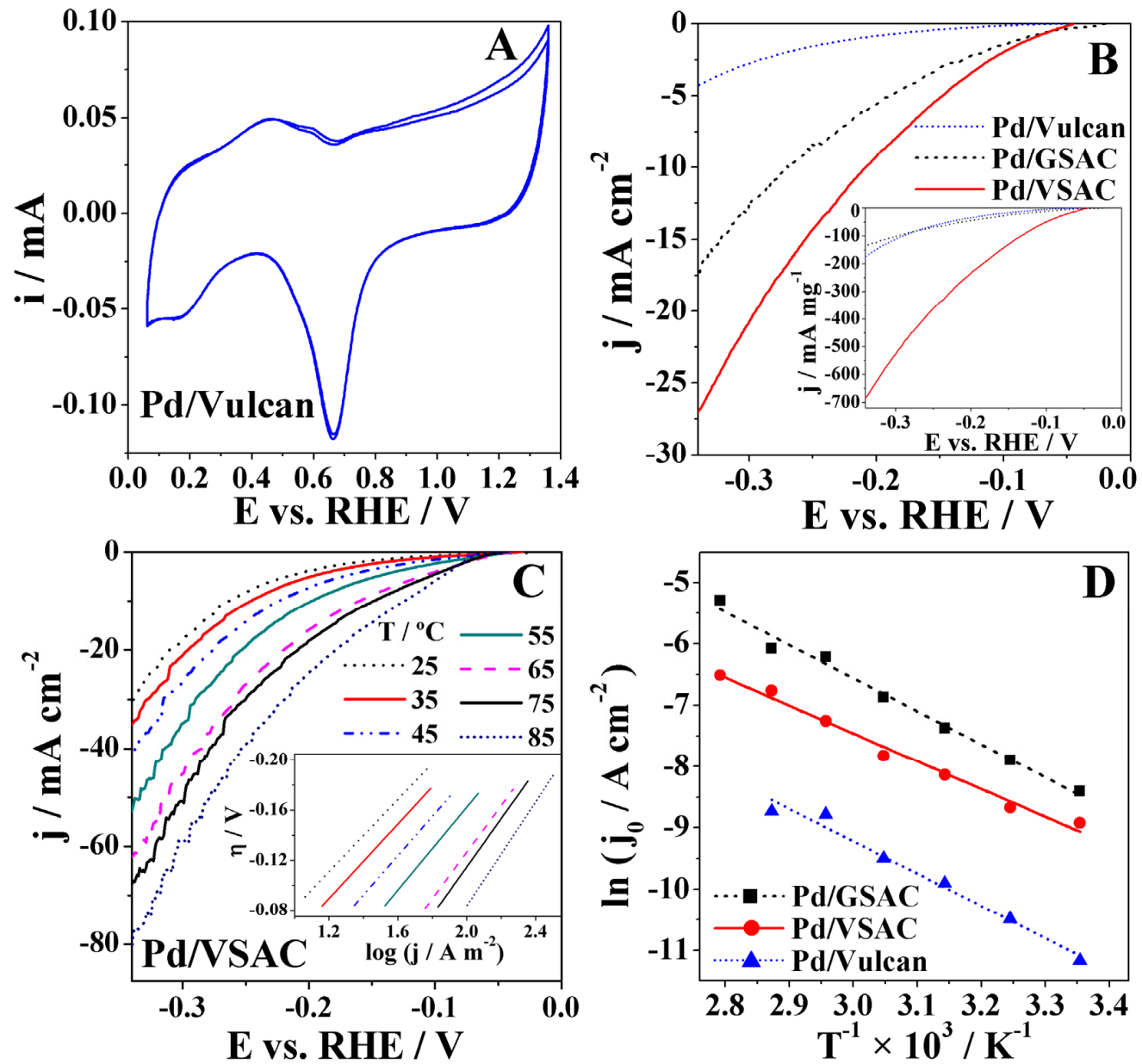

Figure 3. (A) Cyclic voltammetry curve of Pd/Vulcan in deaerated electrolyte solution; (B) Polarisation curves of Pd/GSAC, Pd/VSAC, and Pd/Vulcan at scan rate of $1 \mathrm{mV} \mathrm{s}^{-1}$ with corresponding mass-specific current densities shown as inset; (C) Polarisation curves of Pd/VSAC at different temperatures and the corresponding Tafel plots as inset; (D) Arrhenius plots for the three tested hydrogen evolution reaction (HER) electrocatalysts. All experiments done in $8 \mathrm{M} \mathrm{KOH}$ at room temperature, unless otherwise noted.

\subsection{HER Studies}

Cathodic polarisation curves were run in $8 \mathrm{M} \mathrm{KOH}$ from the OCP until $-0.34 \mathrm{~V}$, at a scan rate of $1 \mathrm{mV} \mathrm{s}^{-1}$ at temperatures ranging from 25 to $85{ }^{\circ} \mathrm{C}$ (cf. Figure $\mathrm{S} 1$ of supporting information). It is known that $\mathrm{H}_{\text {ads }}$ can be absorbed into the Pd lattice, resulting in the formation of a Pd hydride [30]. This absorption can influence the rate at which the reaction occurs since, if not mitigated, it can compete with the Tafel and Heyrovský steps. Considering this, it was necessary to assure that the electrode would be saturated with hydrogen at an equilibrium stage before the measurements took place, leaving no space for $\mathrm{H}_{\mathrm{ads}}$ to be absorbed into the Pd NPs during cathodic polarisation [30]. To prevent this detrimental effect and stabilise the OCP values of the three studied electrodes, a constant potential of $-0.2 \mathrm{~V}$ was applied for $15 \mathrm{~min}$ before the measurements. The OCP values for Pd/GSAC, Pd/VSAC, and $\mathrm{Pd} /$ Vulcan were $-0.03 \mathrm{~V},-0.04 \mathrm{~V}$, and $-0.03 \mathrm{~V}$, respectively.

A low scan rate $\left(1 \mathrm{mV} \mathrm{s}^{-1}\right)$ is necessary since the kinetic parameters, namely, exchange current densities $j_{0}$ and Tafel slopes $b$, should ideally be determined under stationary conditions, assuming electron transfer control and validity of the $j-\eta$ logarithmic approximation. The polarisation curves for the Pd/VSAC electrocatalyst show significantly higher current densities and mass-specific current densities, attaining values as high as $27 \mathrm{~mA} \mathrm{~cm}{ }^{-2}$ and $685 \mathrm{~mA} \mathrm{mg}^{-1}$, respectively, at $25^{\circ} \mathrm{C}$ 
(Figure 3B). These current densities are higher than those reported for HER at reduced graphene oxide (rGO)-supported Pd alloys, namely rGO--Fe ${ }_{48} \mathrm{Pd}_{52}$ of ca. $5 \mathrm{~mA} \mathrm{~cm}{ }^{-2}$ and $\mathrm{rGO}-\mathrm{Au}_{48} \mathrm{Pd}_{52}$ of ca. $18 \mathrm{~mA} \mathrm{~cm}^{-2}$ at potential of $-0.35 \mathrm{~V}$ in $8 \mathrm{M} \mathrm{KOH}$ at $25^{\circ} \mathrm{C}$ [31]. In fact, despite the obvious better performance of the $\mathrm{Pd} / \mathrm{VSAC}$ electrocatalyst demonstrated by the attained high current densities, its superiority is even more evident when considering the actual Pd mass loadings (inset of Figure 3B). The specific current densities are much higher than that obtained at $\mathrm{PdX}$ zeolite of ca. $20 \mathrm{~mA} \mathrm{mg}^{-1}$ at a potential of $-0.35 \mathrm{~V}$ in $8 \mathrm{M} \mathrm{KOH}$ at $25^{\circ} \mathrm{C}$ [32].

The Pd/GSAC and Pd/VSAC electrocatalysts show the expected HER behaviour, with a significant increase in current densities accompanying the increase in temperature. The polarisation curve obtained for the $\mathrm{Pd}$ /Vulcan electrocatalyst did not show this behaviour, possibly due to hydrogen bubbling obstructing the electrode surface at higher temperatures [33].

For further study of HER kinetics at the three electrocatalysts, Tafel plots were constructed based on the data from the polarisation curves, using the classic Tafel relation (Equation (7)),

$$
\eta=a+b \log j=\frac{2.3 \mathrm{R} T}{\alpha \mathrm{F}} \log j_{0}+\frac{2.3 \mathrm{R} T}{\alpha \mathrm{F}} \log j
$$

where $\mathrm{R}$ is the universal gas constant $\left(8.314 \mathrm{~J} \mathrm{~mol}^{-1} \mathrm{~K}^{-1}\right), T$ the temperature in Kelvin and $\mathrm{F}$ is Faraday's constant $\left(96485 \mathrm{C} \mathrm{mol}^{-1}\right)$. The intercept value, $a$, is related with the exchange current density, which indicates the intrinsic rate of electron transfer. The Tafel slope is an indicator of the rate at which the current density increases with the increase of the overpotential. Furthermore, the charge transfer coefficient, $\alpha$, may be determined from the slope. As an example, the inset of Figure 3C shows the Tafel plots obtained from the polarisation curves of Pd/VSAC at the seven different tested temperatures.

The HER data for Pd/VSAC and Pd/GSAC showed a good adjustment to the Tafel equation in the -0.08 to $-0.20 \mathrm{~V}$ overpotential region, with $R^{2}>0.99$. Table 2 shows the $\alpha, b$, and $j_{0}$ values evaluated for the three studied electrocatalysts, as well as the recorded values of current density at overpotential of $0.1 \mathrm{~V}, j_{0.1}$, and of overpotential at $10 \mathrm{~mA} \mathrm{~cm}^{-2}, \eta_{10}$.

Table 2. HER kinetic parameters calculated for the three tested electrocatalysts.

\begin{tabular}{|c|c|c|c|c|c|c|}
\hline Electrode & $\mathrm{T}^{\circ} \mathrm{C}$ & $\alpha$ & $b / \mathrm{V} \mathrm{dec}^{-1}$ & $j_{0} / \mathrm{mA} \mathrm{cm}^{-2}$ & $j_{0.1} * / \mathrm{mA} \mathrm{cm}^{-2}$ & $\eta_{10} * * / \mathrm{V}$ \\
\hline \multirow{7}{*}{ Pd/GSAC } & 25 & 0.36 & 0.163 & 0.13 & 0.76 & 0.299 \\
\hline & 35 & 0.36 & 0.168 & 0.17 & 0.96 & 0.281 \\
\hline & 45 & 0.35 & 0.178 & 0.29 & 1.27 & 0.269 \\
\hline & 55 & 0.34 & 0.190 & 0.40 & 1.70 & 0.256 \\
\hline & 65 & 0.31 & 0.213 & 0.71 & 2.83 & 0.222 \\
\hline & 75 & 0.30 & 0.230 & 1.16 & 3.54 & 0.203 \\
\hline & 85 & 0.34 & 0.208 & 1.48 & 4.64 & 0.171 \\
\hline \multirow{7}{*}{$\mathrm{Pd} / \mathrm{VSAC}$} & 25 & 0.41 & 0.144 & 0.22 & 1.43 & 0.224 \\
\hline & 35 & 0.41 & 0.148 & 0.37 & 2.02 & 0.207 \\
\hline & 45 & 0.40 & 0.156 & 0.63 & 3.04 & 0.185 \\
\hline & 55 & 0.39 & 0.165 & 1.04 & 4.50 & 0.158 \\
\hline & 65 & 0.36 & 0.185 & 1.99 & 7.69 & 0.111 \\
\hline & 75 & 0.36 & 0.192 & 2.29 & 8.90 & 0.109 \\
\hline & 85 & 0.34 & 0.207 & 5.02 & 12.6 & 0.085 \\
\hline \multirow{7}{*}{ Pd/Vulcan } & 25 & 0.56 & 0.105 & 0.01 & 0.10 & $>0.3$ \\
\hline & 35 & 0.44 & 0.137 & 0.03 & 0.18 & $>0.3$ \\
\hline & 45 & 0.39 & 0.162 & 0.05 & 0.28 & $>0.3$ \\
\hline & 55 & 0.37 & 0.175 & 0.07 & 0.39 & $>0.3$ \\
\hline & 65 & 0.38 & 0.189 & 0.11 & 0.62 & $>0.3$ \\
\hline & 75 & 0.35 & 0.194 & 0.15 & 0.69 & $>0.3$ \\
\hline & 85 & 0.34 & 0.202 & 0.16 & 0.55 & $>0.3$ \\
\hline
\end{tabular}

$* j_{0.1}$ and ${ }^{* *} \eta_{10}$ stand for the current density at overpotential of $0.1 \mathrm{~V}$ and for the overpotential at $10 \mathrm{~mA} \mathrm{~cm}{ }^{-2}$, respectively. 
The Tafel slopes of the Pd/GSAC, Pd/VSAC, and Pd/Vulcan XC72 at $25{ }^{\circ} \mathrm{C}$ were found to be $0.163,0.144$, and $0.105 \mathrm{~V} \mathrm{dec}^{-1}$, respectively. The obtained values suggest that the Volmer step is the rate-determining step (RDS) of the process. Tafel slope value deviations from the theoretical value of $0.120 \mathrm{~V} \mathrm{dec}^{-1}$ for the Volmer step as the RDS [34] have been previously reported and explained by the mentioned absorption of hydrogen into the Pd bulk [2,35]. Additionally, it was observed that $b$ values obtained at the three electrocatalysts increased with temperature, which is also reflected in a small decrease of $\alpha$. In contrast, there was a significant increase of the $j_{0}$ values, indicative of faster HER kinetics at higher temperatures. Pd/VSAC gave the highest HER $j_{0}$ values (as high as $5.02 \mathrm{~mA} \mathrm{~cm}{ }^{-2}$ at $85{ }^{\circ} \mathrm{C}$ ). It is worth noting that $j_{0}$ values obtained at Pd/VSAC (for instance, $0.22 \mathrm{~mA} \mathrm{~cm}^{-2}$ at $\left.25^{\circ} \mathrm{C}\right)$ are one order of magnitude higher than those obtained at Pd/Vulcan $\left(0.01 \mathrm{~mA} \mathrm{~cm}^{-2}\right.$ at $25^{\circ} \mathrm{C}$ ). Furthermore, the HER $j_{0}$ values obtained with Pd grafted onto the novel VSAC support are higher than those reported for two Pd-modified carbon fibre electrodes, of $0.16 \mathrm{~mA} \mathrm{~cm}^{-2}$ and $0.02 \mathrm{~mA} \mathrm{~cm}^{-2}$, in alkaline $0.1 \mathrm{M} \mathrm{NaOH}$ electrolyte at room temperature [36,37]. The obtained values are also higher than that reported for Pd-ion exchanged $\mathrm{X}$ zeolite $\left(0.04 \mathrm{~mA} \mathrm{~cm}^{-2}\right)$ in $8 \mathrm{M} \mathrm{KOH}$ at $25{ }^{\circ} \mathrm{C}$ [32]. Chen et al. [38] also evaluated Pd-based catalysts supported on carbon nanofibre and reported a $j_{0}$ of $1.53 \mathrm{~mA} \mathrm{~cm}^{-2}$, similar to those obtained herein. To allow a better comparison of the recorded cathodic polarisation data for the three tested electrocatalysts, Table 1 also includes the current densities at the overpotential of $0.1 \mathrm{~V}, j_{0.1}$, and the overpotential required to attain a current density of $10 \mathrm{~mA} \mathrm{~cm}^{-2}, \eta_{10}$. Both bio-based-supported Pd electrocatalysts presented $j_{0.1}$ values one order of magnitude higher than those obtained for Pd/Vulcan, with Pd/VSAC $j_{0.1}$ values being about double those of Pd/GSAC. Pd/VSAC HER current densities reach the value of $10 \mathrm{~mA} \mathrm{~cm}^{-2}$ at a potential of $-0.21 \mathrm{~V}$ at $25^{\circ} \mathrm{C}$, which is much lower than that at $\mathrm{Pd} /$ Vulcan (below $-0.34 \mathrm{~V}$ ), indicating significantly higher catalytic activity toward HER of the former electrocatalyst. The Pd/Vulcan electrocatalyst led to the lowest current densities, with maximum values between 4 and $5 \mathrm{~mA} \mathrm{~cm}{ }^{-2}$ being attained at an overpotential of $0.3 \mathrm{~V}$. Table 1 also shows the expected overpotential decrease with temperature increase to reach the current density of $10 \mathrm{~mA} \mathrm{~cm}^{-2}$.

The activation energies $E_{\mathrm{a}}$ of HER at these three electrocatalysts were also determined. For this purpose, the values of $j_{0}$ were plotted as a function of the reciprocal value of temperature $1 / \mathrm{T}$ (Figure 3D). The Arrhenius equation (Equation (8)) was then used to examine the results:

$$
\ln j_{0}=\ln A_{i}-\frac{E_{\mathrm{a}}}{\mathrm{RT}}
$$

where $A_{i}$ represents the Arrhenius pre-exponential factor. The data show a good adjustment to the Arrhenius equation with $R^{2}>0.97$. Thus, HER activation energy values of 38,45 , and $44 \mathrm{~kJ} \mathrm{~mol}^{-1}$ were determined for $\mathrm{Pd} / \mathrm{VSAC}, \mathrm{Pd} / \mathrm{GSAC}$ and $\mathrm{Pd} /$ Vulcan, respectively. These values are comparable with the $E_{\mathrm{a}}$ value of $39 \mathrm{~kJ} \mathrm{~mol}^{-1}$ obtained for HER at the PdX zeolite [32] and comparable to/higher than the $E_{\mathrm{a}}$ value of $30 \mathrm{~kJ} \mathrm{~mol}^{-1}$ obtained for HER at pure Pd [39]. However, it should be pointed out that the use of novel activated bio-based carbon supports is extremely useful in reducing the electrocatalyst cost as a result of the significantly lower amount of Pd used.

Subsequently, chronoamperometry (CA) measurements were carried out at potentials of -0.14 , -0.24 , and $-0.34 \mathrm{~V}$ at temperatures ranging from 25 to $85^{\circ} \mathrm{C}$ (Figure 4 ). In agreement with the LSV results, the highest HER current densities were obtained at Pd/VSAC, independently of the applied potential and temperature.

As expected, improvement of the HER kinetics with an increase of overpotential and temperature is evident for all three electrocatalysts. The increase of current density with temperature was the most pronounced in the case of Pd/VSAC. As the temperature and the applied potential are increased, more noise could also be observed, even though the effective current remains quite stable; the observed noise is likely due to enhanced production of hydrogen on the electrode surface. 

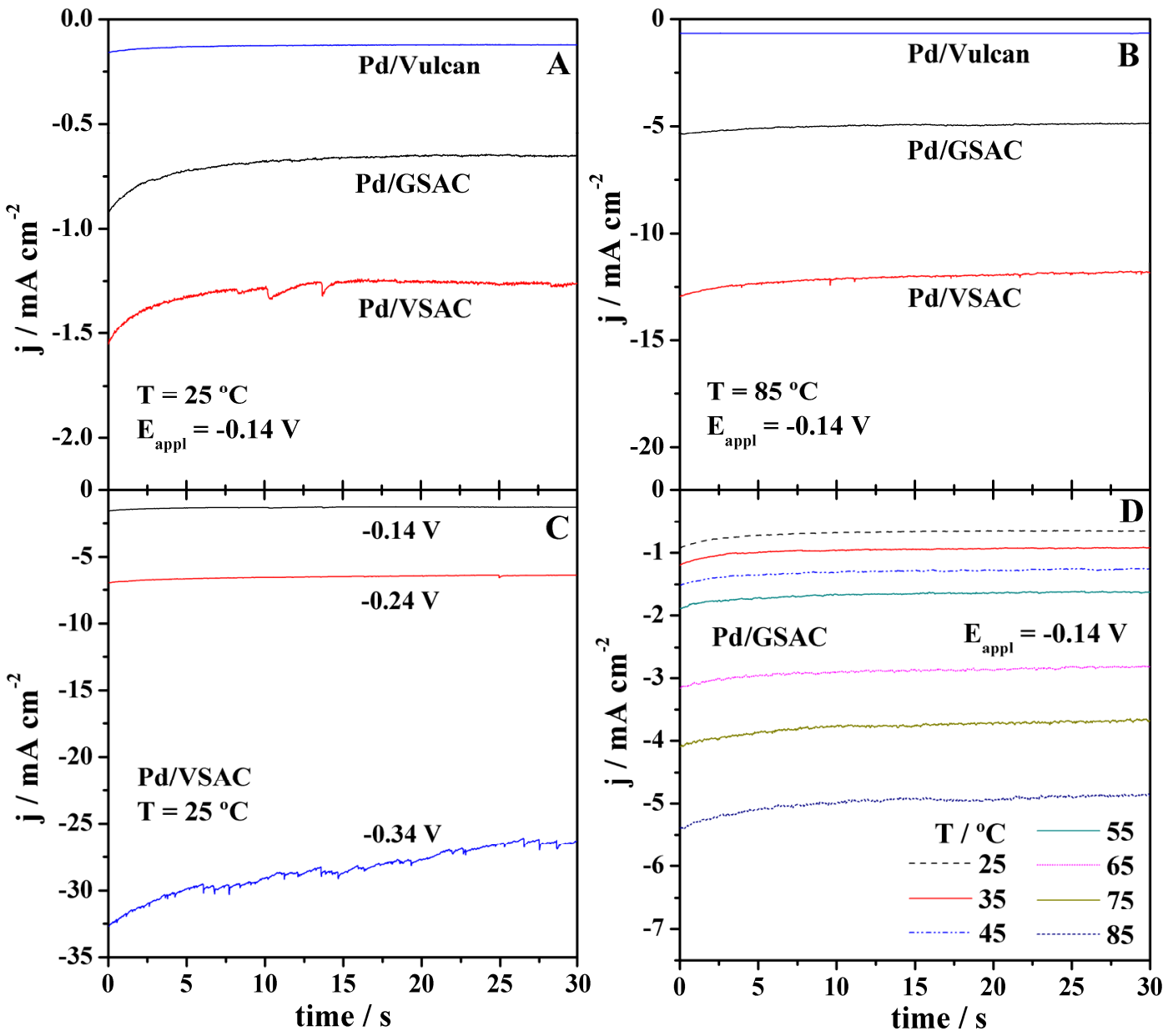

Figure 4. Chronoamperometry measurements in $8 \mathrm{M} \mathrm{KOH}$ of the three electrocatalysts at $-0.14 \mathrm{~V}$ and temperature of (A) $25^{\circ} \mathrm{C}$ and (B) $85^{\circ} \mathrm{C}$; of (C) Pd/VSAC at potentials of $-0.14,-0.24$, and $-0.34 \mathrm{~V}$ and temperature of $25^{\circ} \mathrm{C}$; and of (D) Pd/GSAC at $-0.14 \mathrm{~V}$ and temperatures ranging from 25 to $85^{\circ} \mathrm{C}$.

Besides a high activity for the HER, the stability of the electrodes operating under water electrolysers' harsh conditions is one of the key parameters when choosing the electrode material. The stability of the herein-studied electrocatalysts' activity was evaluated first by continuous cycling for 3000 cycles. Figure 5A shows the LSVs of the three materials recorded at $1 \mathrm{mV} \mathrm{s}^{-1}$ before and after this continuous cycling, revealing the electrocatalysts' stable activity, with a slight decrease of current densities in the cases of Pd/VSAC and Pd/Vulcan. Furthermore, the stability of the electrode activity was evaluated by recording CA curves for $2 \mathrm{~h}$ (Figure 5B). Current densities remained constant during the whole period. Again, LSVs were recorded before and after CA study and showed unchanged current densities (not shown). Optical observations before and after the stability tests did not show any modifications nor characteristics of poor stability of the prepared electrodes.

The VSAC bio-based carbon tested herein has led to interesting results, which make it a promising candidate as a support for HER electrocatalysts. 

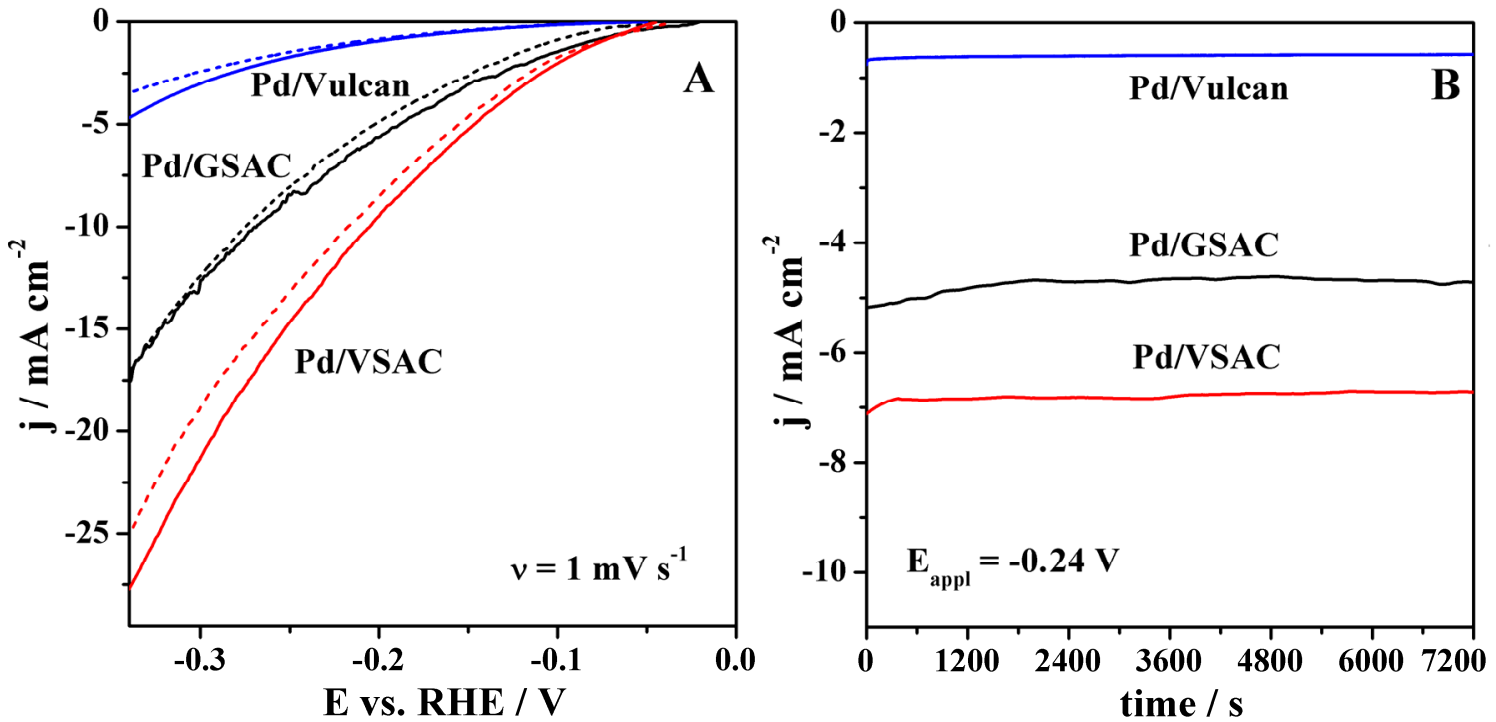

Figure 5. Stability behaviour of the electrocatalysts in $8 \mathrm{M} \mathrm{KOH}$ at room temperature evaluated by (A) cathodic polarisation curves run at $1 \mathrm{mV} \mathrm{s}^{-1}$ before (full lines) and after (dashed lines) 3000 consecutive cycles at $100 \mathrm{mV} \mathrm{s}^{-1}$ and (B) $2 \mathrm{~h}$ stability tests at potential of $-0.24 \mathrm{~V}$.

\section{Experimental}

\subsection{Preparation and Characterisation of Bio-Based Activated Carbon Supports}

Activated bio-based carbons (VSAC and GSAC) were prepared following the procedure described in our previous papers $[27,28]$. Namely, the chemical activation synthesis method was used as this method normally leads to carbons of higher surface area than those obtained by the physical activation method. In the chemical activation method, raw material (dried vine shoots (VS) and grape stalks (GS), in this case) is impregnated with a suitable activation reagent (herein, $\mathrm{ZnCl}_{2}$ was used) and heated in an inert atmosphere. Thus, VS and GS were first impregnated with $\mathrm{ZnCl}_{2}$ (Merck, Darmstadt, Germany) in $\mathrm{ZnCl}_{2} / \mathrm{VS}$ and $\mathrm{ZnCl}_{2} / \mathrm{GS}$ weight ratios of 2 by shaking for 24 and $36 \mathrm{~h}$, respectively. $\mathrm{ZnCl}_{2}$ acts as a dehydrating agent that influences pyrolytic decomposition and inhibits the formation of tar. These impregnated materials were dried at $105^{\circ} \mathrm{C}$ for $24 \mathrm{~h}$. They were subsequently activated by heating up to $700{ }^{\circ} \mathrm{C}$ at a rate of $20^{\circ} \mathrm{C} \mathrm{min}-1$ in a reactor under $\mathrm{CO}_{2}$ flow and held at that temperature for $120 \mathrm{~min}$. The activated bio-based carbon samples were washed with $3 \mathrm{M} \mathrm{HCl}$ (Merck, Darmstadt, Germany) to remove the $\mathrm{Zn}$ compounds and then with cold distilled water until the $\mathrm{pH}$ of the waste water was neutral. Finally, the samples were dried at $105^{\circ} \mathrm{C}$ for $24 \mathrm{~h}$.

The prepared samples were characterised by BET surface area, total pore volume, and pore size (Micromeritics ASAP 2020, Micromeritics Instrument Corporation, Norcross, GA, USA), quantitative surface functional group analysis by Boehm's titration [40], elemental analysis (LECO CHNS 932 Elemental Analyser, LECO Corporation; Saint Joseph, MI, USA), point zero charge $\left(\mathrm{pH}_{\mathrm{pzc}}\right)$ [29], and scanning electron microscopy with energy dispersive X-ray (SEM-EDX, JEOL/JSM-6510 LV, JEOL Ltd., Tokyo, Japan) analysis for the surface morphology and composition.

The specific surface area, total pore volume, and pore size of the samples were determined using $\mathrm{N}_{2}$ adsorption/desorption isotherm data at $77 \mathrm{~K}$. The samples were first degassed at $300{ }^{\circ} \mathrm{C}$ for $16 \mathrm{~h}$ and then analysed. The BET surface area values were calculated from the linear fit of the Brunauer-Emmett-Teller (BET) equation to the relative pressure $\left(P / P^{0}\right)$ range of $0.05-0.20$. The total pore volume (VT) was derived from the amount of $\mathrm{N}_{2}$ adsorbed at relative pressure $\left(P / P^{0}\right)$ of 0.99 . The pore size was calculated from the relation $4 \mathrm{VT} / \mathrm{BET}$ surface area. All calculations for determining the BET surface area, total pore volume, and pore size were performed using ASAP 2020 software integrated to the surface identification device. 


\subsection{Preparation and Characterisation of Activated Carbon-Supported Pd Nanoparticles}

Oleylamine (OAm)-mediated synthesis was used to prepare monodispersed Pd NPs following a protocol described in the literature [41]. In a four-neck glass reactor under nitrogen flow, $0.25 \mathrm{mmol}$ of palladium acetylacetonate ( $\mathrm{Pd}(\mathrm{acac})_{2}$, Sigma-Aldrich, $99 \%$, St. Louis, MO, USA) was dissolved in $10 \mathrm{~mL}$ of OAm (Sigma-Aldrich, 70\%), and then heated at $60{ }^{\circ} \mathrm{C}$ by using a thermocouple temperature-controlled system for $10 \mathrm{~min}$. A quantity of $0.015 \mathrm{~g}$ of borane tert-butylamine complex (97\%, 180211 Aldrich) dissolved in $3 \mathrm{~mL}$ of OAm was then added to the mixture, still at $60{ }^{\circ} \mathrm{C}$, which acquired a dark brown colour, indicating the formation of the Pd NPs. This solution was then heated at $90{ }^{\circ} \mathrm{C}$ for $60 \mathrm{~min}$ and then cooled down to $40{ }^{\circ} \mathrm{C}$. The cooled solution was divided in two centrifuged tubes with $40 \mathrm{~mL}$ of ethanol added to each of them and subjected to centrifugation at $8500 \mathrm{rpm}$ for $12 \mathrm{~min}$. After that, the NPs, which were stuck to the tube walls, were redispersed in hexane. The prepared activated bio-based carbon supports were then added to the hexane NP dispersion. In order to ensure that there was complete adherence of the NPs to the supports, the resulting dispersion was sonicated for $2 \mathrm{~h}$. Once the hexane evaporated, surfactants were removed from the surface of the Pd NPs by adding acetic acid to the mixture and holding it at $70{ }^{\circ} \mathrm{C}$ for $10 \mathrm{~h}$. Following cooling, ethanol was twice added to the dispersion which was then centrifuged. Finally, Pd NPs supported on the activated bio-based carbons were recovered by adding acetone and leaving it to evaporate. For comparison purposes, Pd was also anchored in commercial Vulcan XC72 (Cabot Corporation, Boston, MA, USA) following the same procedure.

The structure of the carbon-supported Pd electrocatalysts was examined by XRD using a Rigaku RadB Dmax X-ray diffractometer (Rigaku Corporation, Tokyo, Japan) with $\mathrm{Cu} \mathrm{K} \alpha$ radiation within a $2-80^{\circ} 2 \theta$ range with a $0.02^{\circ}$ step at a rate of $6^{\circ} \mathrm{min}^{-1}$. Their morphology and composition were examined by SEM-EDX using a JEOL/JSM-6510 LV and by transmission electron microscopy (TEM) using a HITACHI H-8100 microscope (Hitachi, Ltd. Corporation, Tokyo, Japan).

\subsection{Electrode Preparation}

The catalytic inks were prepared by mixing $5 \mathrm{mg}$ of the corresponding Pd-bio-based carbon powder electrocatalyst (Pd/GSAC or Pd/VSAC) in $125 \mu \mathrm{L}$ of $2 \%$ polyvinylidene difluoride (PVDF, Alfa Aesar) solution in N-methyl-2-pyrrolidone (NMP, Sigma-Aldrich). A quantity of $1 \mu \mathrm{L}$ of this solution was deposited onto the surface of a glassy carbon disc electrode of $0.07 \mathrm{~cm}^{2}$ surface area. The electrodes were then left overnight in the oven at a temperature of $80{ }^{\circ} \mathrm{C}$ in order to dry and promote the adhesion of the electrocatalytic ink to their surface.

\subsection{Electrochemical Measurements}

A conventional three-electrode setup with an ALS/DY 2325 bipotentiostat (BAS-Inc., Tokyo, Japan) was used for the electrochemical characterisation of the prepared electrodes. The Pd-bio-based carbon electrodes were used as the working electrodes, the counter electrode was a Pt coil (BAS Inc., Tokyo, Japan), and the reference electrode was a saturated calomel electrode (SCE, Hannah Instruments, HI 5412, Winslet, RI, USA). In order to convert the measured potential values to the reversible hydrogen electrode (RHE) scale, a standard procedure [42] was carried out, where the potential value ( $-1.16 \mathrm{~V}$ vs. SCE) at which the Pt electrode crosses zero current was found by linear scan voltammetry at $10 \mathrm{mV} \mathrm{s}^{-1}$. This measured value was used in the formula $E_{\mathrm{RHE}}=E_{\mathrm{SCE}}+1.16 \mathrm{~V}$. Thus, all potential values in the paper are given relative to RHE. The $8 \mathrm{M} \mathrm{KOH}$ (AnalaR NORMAPUR, $87 \mathrm{wt} \%$ ) electrolyte solution was prepared with Millipore water. This concentration corresponds to ca. $34 \mathrm{wt} \%$, which is identical to the $\mathrm{KOH}$ concentration commonly used in industrial alkaline electrolysers.

Electrochemical characterisation of the electrocatalysts was performed by recording cyclic voltammograms in $\mathrm{N}_{2}$-saturated electrolyte solution in the -0.06 to $1.36 \mathrm{~V}$ potential range at a scan rate of $50 \mathrm{mV} \mathrm{s}^{-1}$. 
The evaluation of HER kinetics at the electrodes was done by linear scan voltammetry measurements in $8 \mathrm{M} \mathrm{KOH}$ solution, starting from the open circuit potential (OCP) up to $-0.34 \mathrm{~V}$, at a scan rate of $1 \mathrm{mV} \mathrm{s}^{-1}$. Chronoamperometry measurements were carried out at three applied potentials $(-0.14 \mathrm{~V},-0.24 \mathrm{~V}$, and $-0.34 \mathrm{~V})$. Measurements were carried out at temperatures ranging from 25 to $85^{\circ} \mathrm{C}$, at $10{ }^{\circ} \mathrm{C}$ intervals. Temperature was controlled by water circulation with an Ultraterm 6000383 P-Selecta bath (J.P. SELECTA S.A., Barcelona, Spain). Stability of the electrodes was evaluated by continuous cycling for 3000 cycles in the range from the OCP up to $-0.34 \mathrm{~V}$ at scan rate of $100 \mathrm{mV} \mathrm{s}^{-1}$ and by recording chronoamperometry curves at potential of $-0.24 \mathrm{~V}$ for $2 \mathrm{~h}$.

\section{Conclusions}

Two novel activated bio-based carbon-supported Pd NP electrocatalysts and a Vulcan XC72-supported Pd NP electrocatalyst were studied for their applicability for HER in typical alkaline water electrolysis conditions. Of the three supports studied, VSAC-supported electrocatalysts showed promising results in terms of high current densities at low overpotentials. The HER Tafel slopes of the Pd/GSAC, Pd/VSAC, and Pd/Vulcan XC72 at $25{ }^{\circ} \mathrm{C}$ were evaluated to be 0.163 , 0.144 , and $0.105 \mathrm{~V} \mathrm{dec}^{-1}$, respectively. The respective exchange current densities were $0.13,0.22$, and $0.01 \mathrm{~mA} \mathrm{~cm}^{-2}$ at $25^{\circ} \mathrm{C}$, while being as high as $1.48,5.02$, and $0.11 \mathrm{~mA} \mathrm{~cm}^{-2}$ at $85^{\circ} \mathrm{C}$. The activation energies were also determined and found to be 45,38 , and $44 \mathrm{~kJ} \mathrm{~mol}^{-1}$ for the Pd/GSAC, Pd/VSAC, and $\mathrm{Pd} /$ Vulcan XC72, respectively. These results show a clear advantage of the VSAC-supported electrocatalyst toward the HER when compared with the other two catalysts. Promising features of the studied material pointed out within this work suggest that Pd NPs supported on VSAC as a novel bio-based carbon support may be a potential alternative as electrodes for the production of $\mathrm{H}_{2}$ by alkaline water electrolysis.

Supplementary Materials: The following are available online at www.mdpi.com/2073-4344/8/2/50/s1, Figure S1: Polarisation curves recorded at scan rate of $1 \mathrm{mV} \mathrm{s}^{-1}$ in $8 \mathrm{M} \mathrm{KOH}$ solution at different temperatures $\left(25-85^{\circ} \mathrm{C}\right)$ and corresponding Tafel plots for Pd/GSAC (A,B), Pd/VSAC (C,D) and Pd/Vulcan (E,F).

Acknowledgments: The authors would like to thank Fundação para a Ciência e a Tecnologia (FCT, Portugal) for postdoctoral research grant no. SFRH/BPD/77768/2011 (B. Šljukić) and for contract no. IF/01084/ 2014/CP1214/CT0003 under IF2014 Programme (D.M.F. Santos).

Author Contributions: M. Erdem and C.A.C. Sequeira conceived and designed the experiments; J.A.S.B. Cardoso performed the experiments; B. Šljukić analysed the data; D.M.F. Santos wrote the paper.

Conflicts of Interest: The authors declare no conflict of interest.

\section{References}

1. Höök, M.; Tang, X. Depletion of fossil fuels and anthropogenic climate change-A review. Energy Policy 2003, 52, 797-809. [CrossRef]

2. Safavi, A.; Kazemi, S.H.; Kazemi, H. Electrocatalytic behaviors of silver-palladium nanoalloys modified carbon ionic liquid electrode towards hydrogen evolution reaction. Fuel 2014, 118, 156-162. [CrossRef]

3. Dixon, R.K. Advancing towards a hydrogen energy economy: Status, opportunities and barriers. Mitig. Adapt. Strateg. Glob. Chang. 2007, 12, 325-341. [CrossRef]

4. Marini, S.; Salvi, P.; Nelli, P.; Pesenti, R.; Villa, M.; Berrettoni, M.; Zangari, G.; Kiros, Y. Advanced alkaline water electrolysis. Electrochim. Acta 2012, 82, 384-391. [CrossRef]

5. Santos, D.M.F.; Sequeira, C.A.C.; Figueiredo, J.L. Hydrogen production by alkaline water electrolysis. Quim. Nova 2013, 36, 1176-1193. [CrossRef]

6. Safizadeh, F.; Ghali, E.; Houlachi, G. Electrocatalysis developments for hydrogen evolution reaction in alkaline solutions-A review. Int. J. Hydrogen Energy 2015, 40, 256-274. [CrossRef]

7. Sawyer, D.T.; Sobkowiak, A.; Roberts, J.L. Electrochemistry for Chemists, 2nd ed.; John Wiley \& Sons: New York, NY, USA, 1995.

8. Zinola, C.F.; Martins, M.E.; Tejera, E.P.; Neves, N.P., Jr. Electrocatalysis: Fundamentals and Applications. Int. J. Electrochem. 2012, 2012, 874687. [CrossRef] 
9. Santos, D.M.F.; Šljukić, B.; Sequeira, C.A.C.; Macciò, D.; Saccone, A.; Figueiredo, J.L. Electrocatalytic approach for the efficiency increase of electrolytic hydrogen production: Proof-of-concept using Pt-Dy. Energy 2013, 50, 486-492. [CrossRef]

10. Yang, L.; Liu, P.; Li, J.; Xiang, B. Two-dimensional material molybdenum disulfides as electrocatalysts for hydrogen evolution. Catalysts 2017, 7, 285. [CrossRef]

11. Eftekhari, A. Electrocatalysts for hydrogen evolution reaction. Int. J. Hydrogen Energy 2017, 42, $11053-11077$. [CrossRef]

12. Šljukić, B.; Santos, D.M.F.; Vujković, M.; Amaral, L.; Rocha, R.P.; Sequeira, C.A.C.; Figueiredo, J.L. Molybdenum Carbide Nanoparticles on Carbon Nanotubes and Carbon Xerogel: Low-Cost Cathodes for Hydrogen Production by Alkaline Water Electrolysis. ChemSusChem 2016, 9, 1200-1208. [CrossRef] [PubMed]

13. Wang, J.; Chen, W.; Wang, X.; Wang, E. N-doped graphene supported $\mathrm{W}_{\mathrm{x}} \mathrm{C}$ composite material as an efficient non-noble metal electrocatalyst for hydrogen evolution reaction. Electrochim. Acta 2017, 251, 660-671. [CrossRef]

14. Li, C.; Bo, X.; Li, M.; Guo, L. Facile electrodeposition fabrication of molybdenum-tungsten sulfide on carbon cloth for electrocatalytic hydrogen evolution. Int. J. Hydrogen Energy 2017, 42, 15479-15488. [CrossRef]

15. Gupta, U.; Rao, C.N.R. Hydrogen generation by water splitting using $\mathrm{MoS}_{2}$ and other transition metal dichalcogenides. Nano Energy 2017, 41, 49-65. [CrossRef]

16. Su, J.; Zhou, J.; Wang, L.; Liu, C.; Chen, Y. Synthesis and application of transition metal phosphides as electrocatalyst for water splitting. Sci. Bull. 2017, 62, 633-644. [CrossRef]

17. Pi, M.; Wu, T.; Guo, W.; Wang, X.; Chen, S. Phase-controlled synthesis of polymorphic tungsten diphosphide with hybridization of monoclinic and orthorhombic phases as a novel electrocatalyst for efficient hydrogen evolution. J. Power Sources 2017, 349, 138-143. [CrossRef]

18. Wang, C.; Zhang, P.; Lei, J.; Dong, W.; Wang, J. Integrated 3D MoSe ${ }_{2} \mathrm{Ni}_{0.85}$ Se nanowire network with synergistic cooperation as highly efficient electrocatalysts for hydrogen evolution reaction in alkaline medium. Electrochim. Acta 2017, 246, 712-719. [CrossRef]

19. Zeng, M.; Li, Y. Recent advances in heterogeneous electrocatalysts for hydrogen evolution reaction. J. Mater. Chem. 2015, 3, 14942-14962. [CrossRef]

20. Bhowmik, T.; Kundu, M.K.; Barman, S. Palladium nanoparticle-graphitic carbon nitride porous synergistic catalyst for hydrogen evolution/oxidation reactions over a broad range of $\mathrm{pH}$ correlation of its catalytic activity with measured hydrogen binding energy. ACS Catal. 2016, 6, 1929-1941. [CrossRef]

21. Limpattayanate, S.; Hunson, M. Electrocatalytic activity of Pt-Pd electrocatalysts for the oxygen reaction in proton exchange membrane fuel cells: Effect of supports. Renew. Energy 2014, 63, 205-211. [CrossRef]

22. Banadaki, A.D.; Amir, K. Recent advances in facile synthesis of bimetallic nanostructures: An overview. J. Nanomater. 2014, 2014, 985948.

23. Tong, S.-S.; Wang, X.-J.; Li, Q.-C.; Han, X.-J. Progress on electrocatalysts of hydrogen evolution reaction based on carbon fiber materials. Chin. J. Anal. Chem. 2016, 44, 1447-1457. [CrossRef]

24. Zhou, W.; Jia, J.; Lu, J.; Yang, L.; Hou, D.; Li, G.; Chen, S. Recent developments of carbon-based electrocatalysts for hydrogen evolution reaction. Nano Energy 2016, 28, 29-43. [CrossRef]

25. Martins, M.; Šljukić, B.; Sequeira, C.A.C.; Metin, Ö.; Erdem, M.; Şener, T.; Santos, D.M.F. Biobased carbon-supported palladium electrocatalysts for borohydride fuel cells. Int. J. Hydrogen Energy 2016, 41, 10914-10922. [CrossRef]

26. Sanders, I.J.; Peeten, T.L. Carbon Black: Production, Properties and Uses; Nova Science Publisher Inc.: New York, NY, USA, 2011.

27. Erdem, M.; Orhan, R.; Şahin, M.; Aydın, E. Preparation and characterization of a novel activated carbon from vine shoots by $\mathrm{ZnCl}_{2}$. Water Air Soil Pollut. 2016, 227, 1-14. [CrossRef]

28. Ozdemir, I.; Sahin, M.; Orhan, R.; Erdem, M. Preparation and characterization of activated carbon from grape stalk by zinc chloride activation. Fuel Process. Technol. 2014, 125, 4588-4589. [CrossRef]

29. Mall, I.; Srivastava, V.; Kumar, G.; Mishra, I. Characterization and utilization of mesoporous fertilizer plant waste carbon for adsorptive removal of dyes from aqueous solution. Colloid Surf. A 2006, 278, 175-187. [CrossRef]

30. Green, T.; Britz, D. Kinetics of the deuterium and hydrogen evolution reactions at palladium in alkaline solution. J. Electroanal. Chem. 1996, 412, 59-66. [CrossRef] 
31. Cardoso, J.A.S.B.; Amaral, L.; Metin, O.; Cardoso, D.S.P.; Sevim, M.; Sener, T.; Sequeira, C.A.C.; Santos, D.M.F. Reduced graphene oxide assembled Pd-based nanoalloys for hydrogen evolution reaction. Int. J. Hydrogen Energy 2017, 42, 3916-3925. [CrossRef]

32. Vasić, M.; Čebela, M.; Pašti, I.; Amaral, L.; Hercigonja, R.; Santos, D.M.F.; Šljukić, B. Efficient hydrogen evolution electrocatalysis in alkaline medium using Pd-modified zeolite X. Electrochim. Acta 2018, 259, 882-892. [CrossRef]

33. Sequeira, C.A.C.; Santos, D.M.F.; Šljukić, B.; Amaral, L. Physics of electrolytic gas evolution. Braz. J. Phys. 2013, 43, 199-208. [CrossRef]

34. Santos, D.M.F.; Amaral, L.; Šljukić, B.; Macciò, D.; Saccone, A.; Sequeira, C.A.C. Electrocatalytic activity of nickel-cerium alloys for hydrogen evolution in alkaline electrolysis. J. Electrochem. Soc. 2014, 161, F386-F390. [CrossRef]

35. Pluntke, Y.; Kibler, L.A. Hydrogen evolution electrocatalysts on AgPd(111) alloys. Electrocatalysis 2011, 2, 192-199. [CrossRef]

36. Pierozynski, B.; Mikolajczyk, T.; Turemko, M.; Czerwosz, E.; Kozlowski, M. Hydrogen evolution reaction at Pd-modified carbon fibre in $0.1 \mathrm{M} \mathrm{NaOH}$. Int. J. Hydrogen Energy 2015, 40, 1795-1799. [CrossRef]

37. Pierozynski, B. Hydrogen evolution reaction at Pd-modified carbon fibre and nickel-coated carbon fibre materials. Int. J. Hydrogen Energy 2013, 38, 7733-7740. [CrossRef]

38. Chen, J.; Chen, J.; Yu, D.; Zhang, M.; Zhu, H.; Du, M. Carbon nanofiber-supported PdNi alloy nanoparticles as highly bifunctional catalysts for hydrogen and oxygen evolution reactions. Electrochim. Acta 2017, 246, 17-26. [CrossRef]

39. Durst, J.; Simon, C.; Hasché, F.; Gasteiger, H.A. Hydrogen oxidation and evolution reaction kinetics on carbon supported Pt, Ir, Rh, and Pd electrocatalysts in acidic media. J. Electrochem. Soc. 2015, 162, F190-F203. [CrossRef]

40. Boehm, H.P. Surface oxides on carbon and their analysis: A critical assessment. Carbon 2002, 40, 145-149. [CrossRef]

41. Mazumder, V.; Sun, S. Oleylamine-mediated synthesis of Pd nanoparticles for catalytic formic acid oxidation. J. Am. Chem. Soc. 2009, 131, 4588-4589. [CrossRef] [PubMed]

42. Sanetuntikul, J.; Hang, T.; Shanmugam, S. Hollow nitrogen-doped carbon spheres as efficient and durable electrocatalysts for oxygen reduction. Chem. Commun. 2014, 50, 9473-9476. [CrossRef] [PubMed] 